\title{
The effect of terpolymer admixtures on physico-mechanical properties of cement pastes
}

\author{
Negim E.S.M ${ }^{1 *}$, Aisha A.M.B. ${ }^{2}$, Yessimkanova U. ${ }^{3}$, Kurmanbekova A. ${ }^{3}$, Tyazhina K. ${ }^{3}$, Urkimbaeva P.I. $^{3}$, \\ Rakhmetullayeva R.K. ${ }^{3}$, Shatabayeva E. ${ }^{3}$, Irmukhametova G. ${ }^{3}$, Mun G. A. ${ }^{3}$, Yeligbayeva G.Zh. ${ }^{4}$, Khatib J.M. ${ }^{1}$ \\ ${ }^{1}$ Faculty of Sciences and Engineering, University of Wolverhampton, Wulfruna Street, Wolverhampton, \\ West Midlands, WV1 1LY, UK \\ ${ }^{2}$ School of Chemical Science, Universiti Sains Malaysia, 11800 Penang, Malaysia \\ ${ }^{3}$ Department of Organic Substances, Chemistry and Technology,Natural Compounds and Polymers, \\ Al-Faraby Kazakh National University, 050038 Almaty, Kazakhstan \\ ${ }^{4}$ K.I. Satpaev Kazakh National Technical University 22, Satpaev avenue, Almaty, 050013, Kazakhstan \\ *Corresponding authorE-mail: elashmawi5@yahoo.com
}

Copyright $(9) 2014$ Negim E.S.M et al. This is an open access article distributed under the Creative Commons Attribution License, which permits unrestricted use, distribution, and reproduction in any medium, provided the original work is properly cited.

\begin{abstract}
Three composition ratios of methyl methacrylate; (MMA), 2-ethylhexyl acrylate, (2- EHA), and methacrylic acid; (MAA) terpolymers were prepared via emulsion polymerization. The polymerizations were carried out at $80^{\circ} \mathrm{C}$ using potassium persulfate (KPS) as initiator. The terpolymers were characterized by FT-IR and ${ }^{1} \mathrm{HNMR}$. The influence of these terpolymers on the physico-mechanical properties of Portland cement (PC) pastes was determined using various characterization methods such as rheological and consistency. The results showed that as the ratio of MMA increased in the terpolymers, the water of consistency decreased, while the initial and final setting times were elongated with the concentration of 2-EHA increases. The workability, combined water and compressive strength of the hardened cement pastes were raised, whereas the water absorption was reduced with increasing quantity of MMA in prepared terpolymers and leads to the reduction in the porosity of the cement pastes, it is due to generation polymer films between cement granules. The SEM images confirmed that the addition of the terpolymers to the cement pastes affected on shape or morphology and size of crystals of the formed hydrates.
\end{abstract}

Keywords: Terpolymer; Cement; Rheological; Strength; SEM; Workability.

\section{Introduction}

Mortar and concrete made with Portland cement has been a popular construction material in the world for the past 170 years or more [1]. However, cement mortar and concrete have some disadvantages such as delayed hardening, low tensile strength, large drying shrinkage, and low chemical resistance. To reduce these disadvantages, many attempts to use polymers have been made. One such attempt is polymer-modified (or polymer cement) mortar or concrete, which is made by the modifying ordinary cement mortar or concrete with polymer additives such as latexes, redispersible polymer powders, water-soluble polymers, liquid resins, and monomers. For example: Kung-Chung et al., [2] synthesized sulfonated phenolic formaldehyde resins (SPF) from phenol, formaldehyde and sodium bisulfate through a four-step reaction. The effect of SPF on the workability of cementitious materials was investigated. The results showed that the adsorption of SNF on cement particles follows a Langmuir isothermal adsorption model. Effective of watersoluble highly sulfonated melamine-formaldehyde resin (HSMF) in concrete was studied. Ahmad [3] prepared (HSMF) by atmospheric reflux from melamine, formaldehyde, sodium sulphite and metabisulphite through a four-step reaction. The results shown that the viscosity of the solutions increased with increasing molecular weight of the polymers until a critical molecular weight, as the number of sulfonated groups of the polymeric chains increases, the solubilizing effect of these groups increase and led to the improvement of the dispersing effects of the resin. So it is expected that the HSMF resin to be a more effective concrete chemical admixtures. El-Sayed et al., [4-20] reported the performance of 
water-soluble copolymers on the rheological properties of Portland cement (PC) pastes and mortar. The results showed that the addition of aqueous solutions from the prepared copolymers to the cement enhance the properties of cement and mortar.

The present study was to investigate the terpolymers activity and properties of ordinary Portland cement pastes containing terpolymer as chemical admixtures. Various formulations were designed to investigate the effect of process variables such as methyl methacrylate (MMA) and 2-ethyl hexyl acrylate (2-EHA) in presence of methacrylic acid (MAA) on the physico-mechanical of ordinary Portland cement.

\section{Experimental}

\subsection{Chemicals}

Methyl methacrylate (MMA), 2-Ethylhexyl acrylate (2-EHA), Methacrylic acid (MAA), sodium dodecyl sulfate (SDS) and potassium persulfate (KPS) were obtained from Sigma Aldrich, USA. All these chemicals were of pure grade and used as received.

The raw materials used in the present study are Portland cement clinker (PCC) and raw gypsum (G). Each of those raw materials was separately ground in a steel ball mill until the surface area of respectively 3650 and $2800 \mathrm{~cm}^{2} / \mathrm{g}$ was achieved. The chemical composition of the raw materials is shown in Table 1. The mineralogical composition of the PCC sample is $\mathrm{C}_{3} \mathrm{~S}, 58.79 \% ; \beta-\mathrm{C}_{2} \mathrm{~S}, 17.68 \% ; \mathrm{C}_{3} \mathrm{~A}, 8.08 \% ; \mathrm{C}_{4} \mathrm{AF}, 9.72 \%$. The Portland Cement (PC) was prepared by mixing $96 \%$ PCC and $4 \%$ G (by weight) in a porcelain ball mill for one hour using 3 balls to ensure complete homogeneity of the cement. The Blaine surface area of the cement sample was $3350 \mathrm{~cm}^{2} / \mathrm{g}[21]$.

Table 1: The Chemical Composition of the Raw Materials, Mass \%.

\begin{tabular}{llllllllll}
\hline Oxides Materials & $\mathrm{SiO}_{2}$ & $\mathrm{Al}_{2} \mathrm{O}_{3}$ & $\mathrm{Fe}_{2} \mathrm{O}_{3}$ & $\mathrm{CaO}$ & $\mathrm{MgO}$ & $\mathrm{SO}_{3}$ & $\mathrm{Na}_{2} \mathrm{O}$ & $\mathrm{K}_{2} \mathrm{O}$ & $\mathrm{L} . \mathrm{O} . \mathrm{I}$ \\
\hline $\mathrm{PCC}$ & 21.48 & 6.03 & 4.22 & 64.29 & 0.68 & 0.39 & 0.21 & 0.11 & 1.32 \\
$\mathrm{G}$ & 0.58 & 0.14 & 0.11 & 30.08 & 0.13 & 45.36 & 0.07 & 0.09 & 22.16 \\
\hline
\end{tabular}

\subsection{Synthesis of the terpolymer}

Terpolymerization of MMA, 2-EHA and MAA were carried out by the technique of semicontinuous emulsion polymerization processes with various ratios of monomers $(M 1=26.5: 62: 11.5),(M 2=62: 26.5: 11.5)$ and $(M 3=44.25$ : 44.25: 11.5) respectively. One type of emulsifier, namely, SDS (5 g) was independently used in the emulsion polymerization processes. The emulsifier was dissolved in $150 \mathrm{~g}$ of distilled water and charged into a $500 \mathrm{ml}$ threenecked flask. The free radical initiation system of KPS ( $1.5 \mathrm{~g})$ was added to the flask during mechanical stirring at 500 rpm. The monomers (100 g) (MMA/2-EHA/ MAA) monomers were added drop wise (about $12 \mathrm{ml} / \mathrm{hr}$ ) during the stirring process at $65^{\circ} \mathrm{C}$ using an automatically controlled water bath under nitrogen atmosphere for a period of $4 \mathrm{hr}$ followed by another $1 \mathrm{hr}$ at $80^{\circ} \mathrm{C}$.

\subsection{Testing}

Chemical composition of terpolymers was verified by FTIR spectra, which were recorded on a Bruker Tensor 37 FTIR spectrometer and ${ }^{1} \mathrm{H}$ NMR (Bruker Avance 300 and 400, Switzerland).

The prepared terpolymers were added to mixing water and then added gradually to $300 \mathrm{~g}$ of the dry cement in order to determine the water of consistency and setting time using Vicat apparatus [22, 23]. The determined water of consistency premixed with the copolymer was added to $500 \mathrm{~g}$ of the dry cement. The resulting cement pastes were directly moulded into one-inch cube stainless steel moulds. The moulds were manually agitated for 2 minutes and then on a vibrator for another 2 minutes to assure the complete removal of air bubbles and voids and to produce suitable pastes. The moulds were kept in a humidity chamber at $100 \% \mathrm{R}$. H and a constant room temperature overnight, then demoulded and cured under water till the time of testing (1, 3, 7 and 28 days) for total porosity and compressive strength [24]. The compressive strength was carried out using a hydraulic testing machine of Type LPM 600 M1 SEIDNER (Germany) having full capacity of $600 \mathrm{KN}$. The loading was applied perpendicular to the direction of the upper surface of the cubes. The total porosity, $\xi$ of each sample at any interval was calculated from the following equation [25]:

$$
\xi=0.99 \mathrm{X} \mathrm{We} X \mathrm{dp} /(1+\mathrm{Wt})
$$

where 0.99 is the specific volume of the free water, We is the evaporable water content, $\mathrm{dp}$ is the bulk density, $\mathrm{g} / \mathrm{cm}^{3}$ and $\mathrm{Wt}$ is the total water content which is equal to the sum of evaporable water (We) and combined water (Wn) contents. The bulk density (dp) was determined from the following equation: $\mathrm{dp}=\mathrm{W} 1 / \mathrm{W} 1-\mathrm{W} 2 \mathrm{~g} / \mathrm{cm}^{3}$, where $\mathrm{W} 1$ is the saturated surface dry weight in air $(\mathrm{g})$ and $\mathrm{W} 2$ is the submerged weight in water $(\mathrm{g})$. To stop the hydration at any age of hydration, a representative sample of about $10 \mathrm{~g}$ after the determination of compressive strength was taken, ground in an alumina mortar containing $50 \mathrm{ml}$ of 1:1 (methanol: acetone) solution mixture and then filtered through a sintered glass funnel (G4). The sample was washed with $50 \mathrm{ml}$ fresh diethyl ether, dried at $70{ }^{\circ} \mathrm{C}$ for one hour and then kept 
inside an airtight bottle as described elsewhere [25]. The curing water was renewed every week. The combined water content (Wn) of samples predried at $105^{\circ} \mathrm{C}$ for 24 hours was determined as the ignition loss at $1000{ }^{\circ} \mathrm{C}$ for 30 minutes [26]. The density test was carried out according to ASTM C127 - 12 [27].

\section{Results and discussion}

\subsection{Characterization of terpolymer}

The structure of prepared terpolymers with different composition of methyl methacrylate, MMA and 2-ethylhexyl acrylate 2- EHA and constant ratio of methacrylic acid MAA (11.5) [(26.5:62), (62:26.5) and (44.25:44.5) wt. \% (M1, M2, and M3)] respectively, was confirmed by FT- IR and ${ }^{1} \mathrm{H}$ NMR as shown in scheme 1.

\subsubsection{FTIR spectra}

FTIR spectra of terpolymers are shown in Figure 1. Spectral changes due to polymer composition are evident. O-H stretching vibration typical of carboxylic groups at range $3441-3414 \mathrm{~cm}^{-1}$ that changes with the MAA content in the synthesized trerpolymer. The $\mathrm{C}=\mathrm{O}$ stretching vibration is typical of the acid carbonyl groups and ester groups at range $1736-1734 \mathrm{~cm}^{-1}$, and the region at 1242 and $1167 \mathrm{~cm}^{-1}$ presents for $\mathrm{C}-\mathrm{O}-\mathrm{C}$ stretch vibrating of ester groups. The $\mathrm{CH}_{2}$ deformation vibrations are clearly observed at range1466 - $1384 \mathrm{~cm}^{-1}$, while $\mathrm{CH}_{3}$ presents as strong peak at region 2960-2919 $\mathrm{cm}^{-1}$ and $\mathrm{CH}$ presents at region between 2875 and $2851 \mathrm{~cm}^{-1}$.

\subsection{2. ${ }^{1} \mathrm{H}$ NMR}

The ${ }^{1} \mathrm{H}$ NMR spectrum provides more evidence for the structure of the prepared terpolymers. The typical spectral for ${ }^{1} \mathrm{H}$ NMR is shown in Figure 2.The chemical shift at $\delta=1-0.9 \mathrm{ppm}$ is a result of protons in CH3 groups, $\delta$ at range 1.2-1.6 ppm for proton in $\mathrm{CH}_{2}$ and $\delta=2.4 \mathrm{ppm}$ for proton in $\mathrm{CH}$ on the ethylhexyl group. The signals at $\delta 3.53-3.65 \mathrm{ppm}$ are assigned to $\mathrm{CH}_{3}$ groups attached to the $\mathrm{COO}$ side groups of MMA. The $\delta$ observed at $4.08 \mathrm{ppm}$ is assigned to protons in $\mathrm{CH}_{2}$ groups attached to the COO side group of 2- EHA.

The prepared terpolymer is expected to have the following structure according the above characteristics as shown in scheme 1.

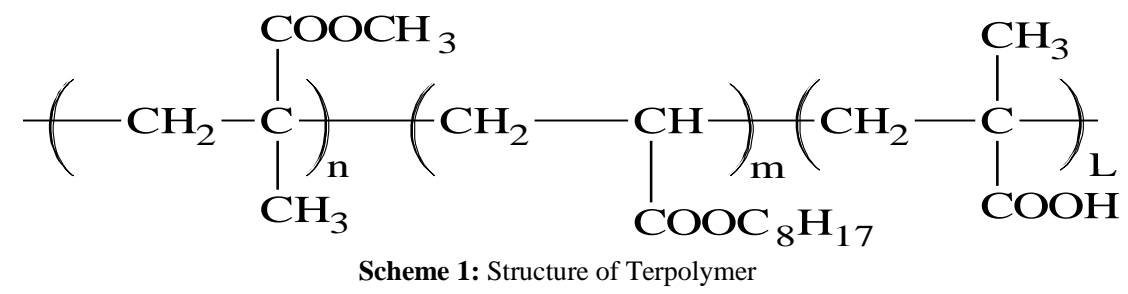

\subsection{Application of terpolymer in cement pastes}

\subsubsection{Water of consistency and setting time}

The results of water of consistency as well as setting time of the OPC (M0) and the various pastes premixed with polymers shown in Figures 3 and 4. The results indicate that decreases in the water cement ratio (W/C) from 0.28 to 0.23 with increasing the ratio of MMA in the terpolymer. The reduction in water of consistency was attributed to the adsorption of the highly polar polymer molecules on the cement particles and hence, the subsequent formation of a polymer film, which reduced the interparticle attraction between the cement particles and then, prevented flocculation or agglomeration for them [27].

Graphically Figure 4 shows the initial and final setting times of cement paste, which was measured as a function of added terpolymers by different ratios (M1, M2, and M3) and without terpolymer M0. The results of influence of polymeric materials on setting times for all samples showed elongating in the initial and final setting times with increasing in the concentration of 2-EHA M1 ratio in the prepared of terpolymers. This may be due to the dispersion action on flocculated cement particles and reduction in the concentration of contact points between different grains [28]. 


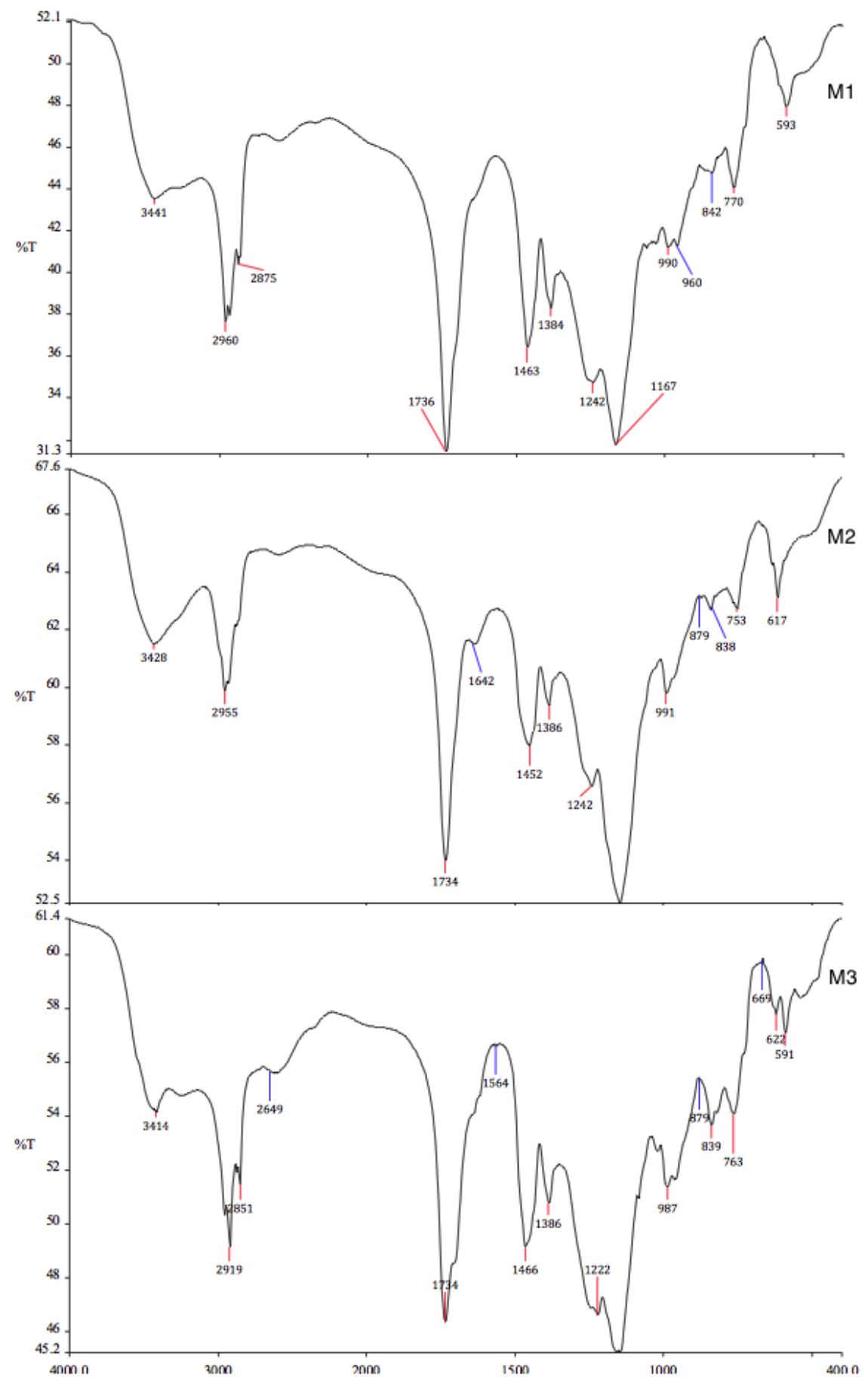

Fig. 1: FTIR Spectra Terpolymers.

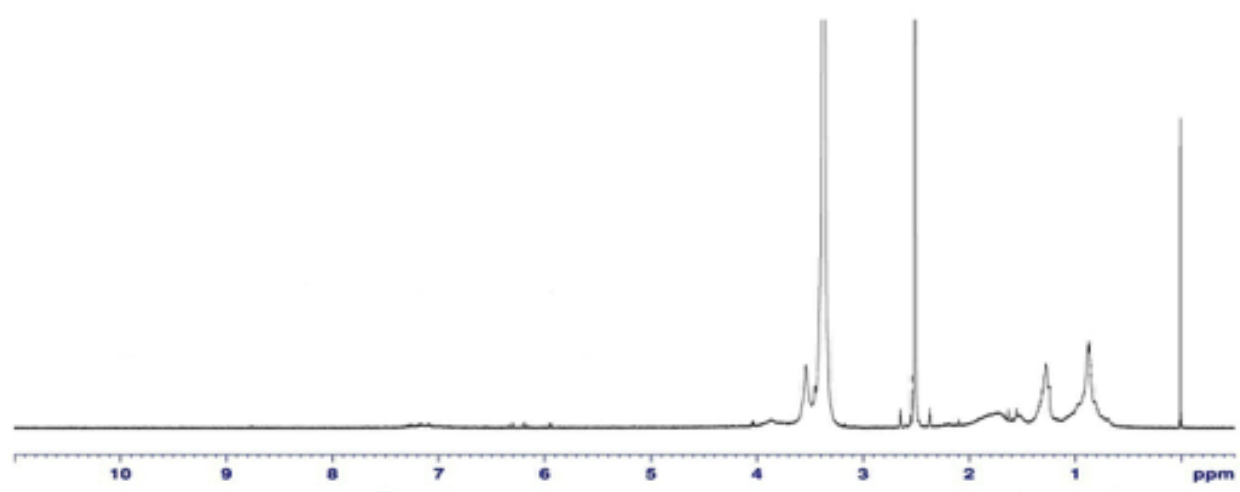

Fig. 2: ${ }^{1} \mathrm{H}$ NMR of Terpolymer in Dmso-D6 


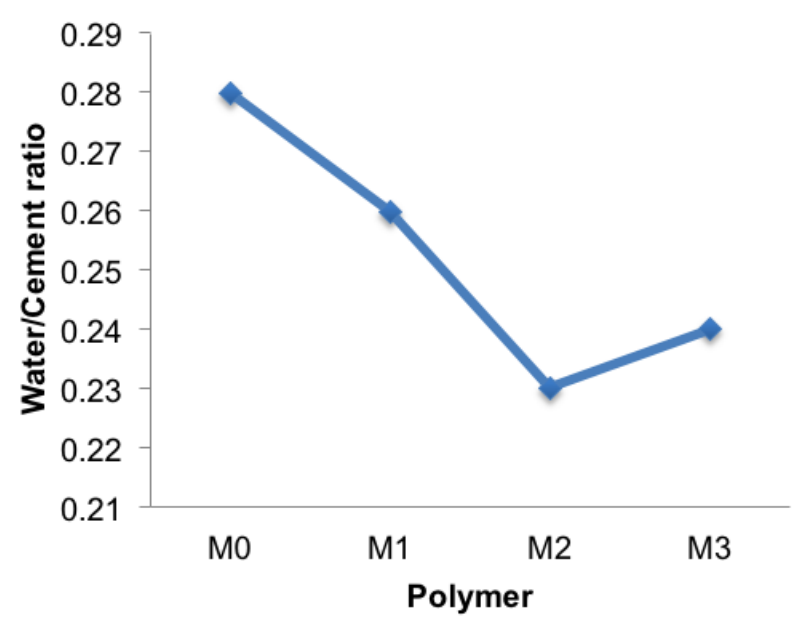

Fig. 3: The Effect of the Terpolymers on the W/C Ratio of the Cement Pastes.

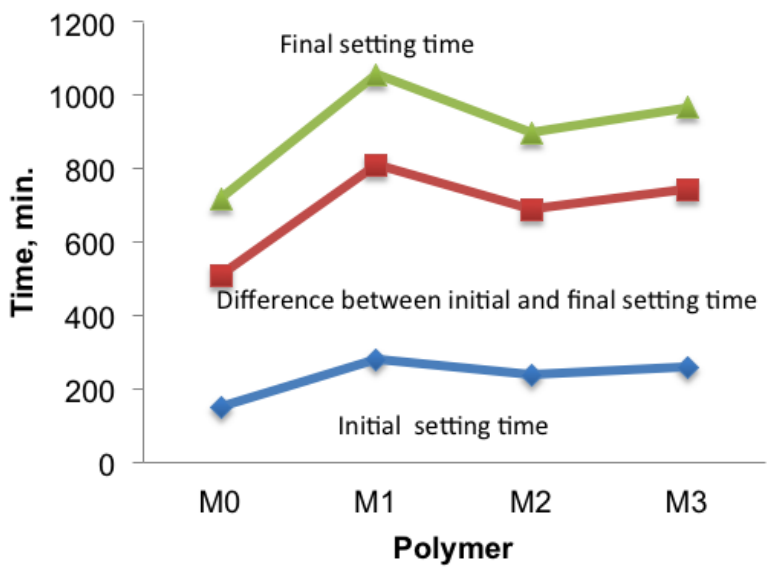

\subsubsection{Workability}

Fig. 4: The Effect of the Terpolymers on the Setting Time of the Cement Pastes

The results of the cement pastes workability tests are presented graphically in Figure 5. This figure shows that the cement paste with added M3 ratio causes the slightest improvement of workability with 148 mm compared to M2 with $146 \mathrm{~mm}$. Enhancement of the cement paste workability is mainly interpreted in terms of improved consistency due to both the 'ball bearing' action and the dispersing effect of polymer [29].

On the other hand, addition of M1 ratio to cement showed a slump measurement of $135 \mathrm{~mm}$. This effect is probably related to poor adsorption behavior between polymer and cement particles [30].

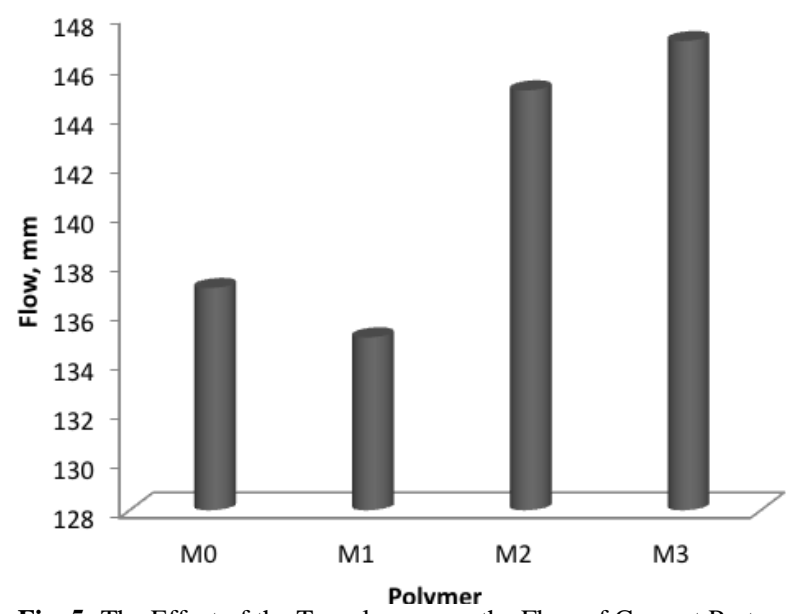

Fig. 5: The Effect of the Terpolymers on the Flow of Cement Pastes 


\subsubsection{Water absorption}

The effect of terpolymers addition on water absorption of hardened cement paste is shown graphically in Figure 6. It is evident that water absorption reduces considerably with increasing the ratio of MMA in prepared polymer. As seen, M2 ratio exhibits the lowest value towered absorption of water, this is due to the large pores in the polymer-modified cement pastes that are filled with polymer particles or sealed with continuous polymer films that leads to reduce the porosity of the pastes [31]. Also, polymer-modified cement pastes are expected to be more resistant towards penetrating aggressive environments than control cement paste [29].



Fig. 6: The Effect of the Terpolymers on the Water Absorption of the Cement Pastes

\subsubsection{Chemically Combined Water Content}

The results of chemically combined water of the cement pastes (M0) and the various of pastes premixed with polymer (M1, M2and M3) are graphically shown as a function of curing time in Figure 7, indicate that the combined water content increases with the increase of curing time. Also, addition of the polymer to the cement increased the chemically combined water content. This leads to an increase in the formation of additional amounts of calcium silicate hydrates as a result of pozzolanic reaction [32]. The cement pastes premixed with (M2) achieved the highest values of combined water contents during the longer stages of hydration 28 days.

Furthermore, the combined water of cement pastes premixed with polymer rises with cement ratio of 0.23 (M2), Figure 8 shows the effect of water/cement ratios on the combined water of cement pastes. It is conceivable that a long lasting close contact of water molecules with cement granules is required for the hydration to occur. In this case of the presence of polymer, they could be gathering around cement granules to form a polymer layer, in which the hydrophobic ends of the polymer are contact with the cement granule surface and their hydrophilic heads orientate towards surrounding water molecules [33].

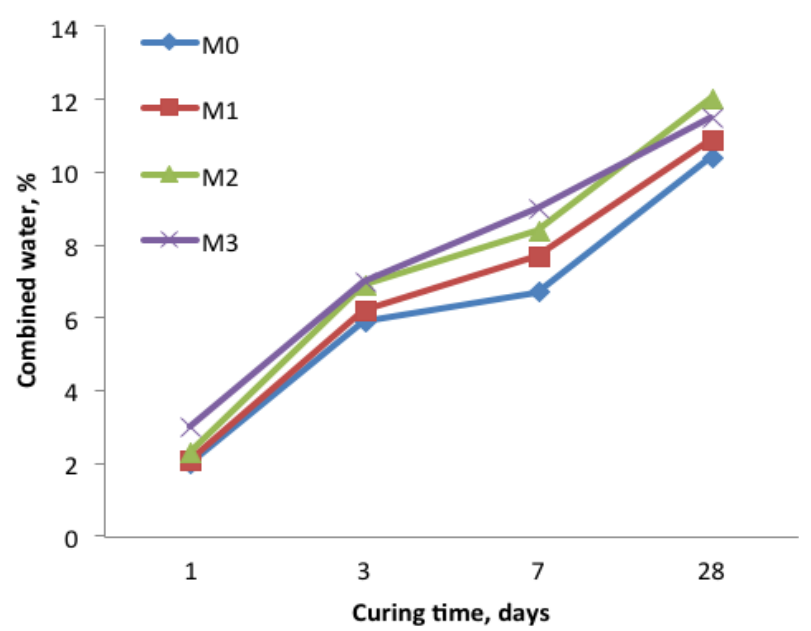

Fig. 7: The Effect of the Terpolymers on the Combined Water of Cement Pastes 


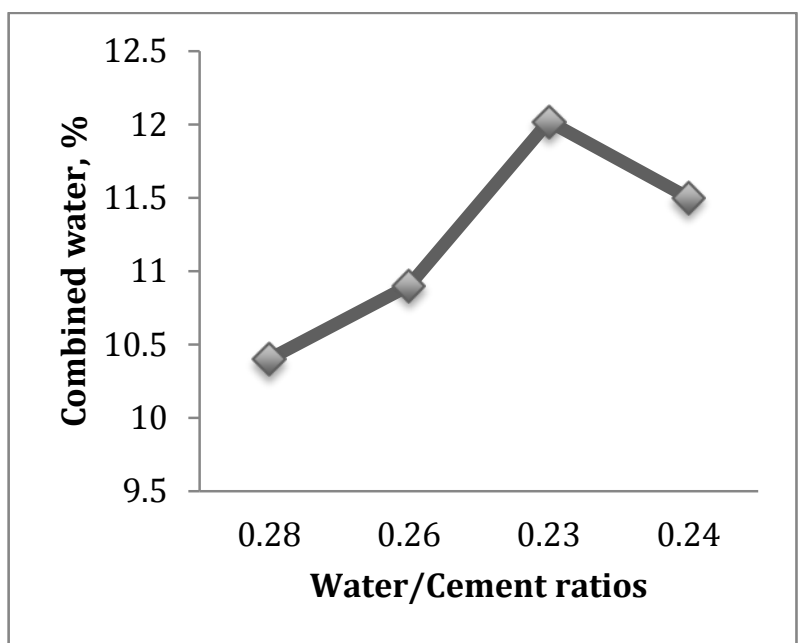

Fig. 8: The Effect of Water/Cement Ratios on the Combined Water of Cement Pastes in Presence of Terpolymer.

\subsubsection{Compressive Strength}

The effect of terpolymers addition on compressive strength of cement pastes is shown in Figure 9, a comparison of the strength values of three ratios of premixed pastes (M1, M2, and M3) shows that the strength values are higher than that of cement pastes M0 at all curing ages, due to the growth of crystalline structures in presence of polymer particles and increases the bonds between the various particles that leads to more dense structure of the hardened cement pastes [34]. The compressive strength values enhance with the addition of the admixture at early and later ages [32].

Moreover, W/C (0.23) ratio of cement pastes premixed with M2 is more significantly effect on compressive strength of pastes, which exhibit the highest strength at about $65 \mathrm{Mpa}$ (Figure 10). The compressive strength is increased with decreasing water cement ratio as same results that obtained by Joachim [35].



Fig. 9: The Effect of the Terpolymers on the Compressive Strength of Cement Pastes

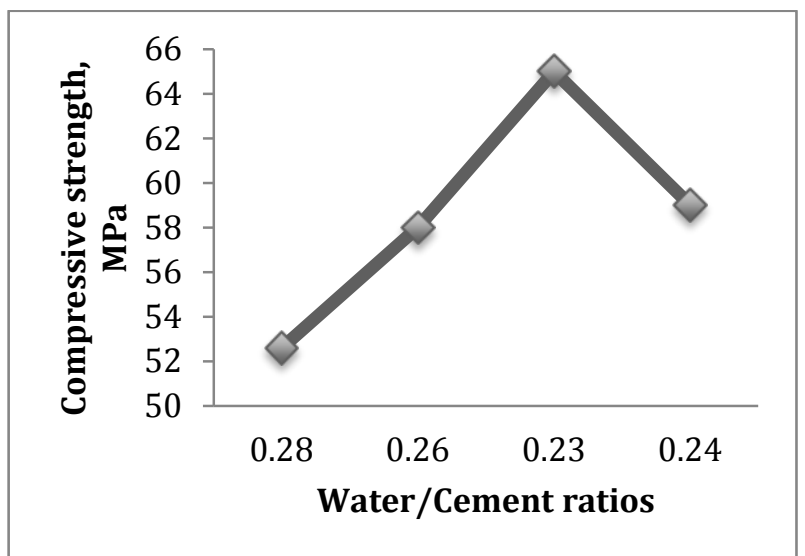

Fig. 10: The Effect of Water/Cement Ratios on the Compressive Strength of the Cement Pastes in Presence of Terpolymers 


\subsubsection{Scanning electron microscopy}

The microstructure of the cement pastes M0 and pastes premixed with terpolymers M1, M2 and M3 are shown in Figure 11. The micrograph of M0 detected the formation of the cement particles that showed the growth of rods of ettringite phase $\left(\mathrm{C}_{3} \mathrm{~A}\right.$. $\left.3 \mathrm{CaSO}_{4} \cdot 32 \mathrm{H}_{2} \mathrm{O}\right)$. The morphology of the $\mathrm{C}-\mathrm{S}-\mathrm{H}$ in the polymer- modifier appears to be slightly different, being less dense than that of the cement pastes. Chandra et al., [36] reported that the retardation effects of in cement/cement admixtures due to the interaction of $\mathrm{Ca}^{2+}$ ions with chemical admixtures, which holds their action and causes the acceleration of early ettringite gel formation or inhibition of the conversion of ettringite to monosulphate $\left(\mathrm{C}_{3} \mathrm{~A} .3 \mathrm{CaSO}_{4} \cdot 12 \mathrm{H}_{2} \mathrm{O}\right)$. The SEM micrograph observations of the cement pastes seem to confirm better hydration of the pastes in the presence of the polymer and the ettringite crystals are much smaller that leads to changes in the morphology of the surface from long and thin to short and compact needles [37].



M0



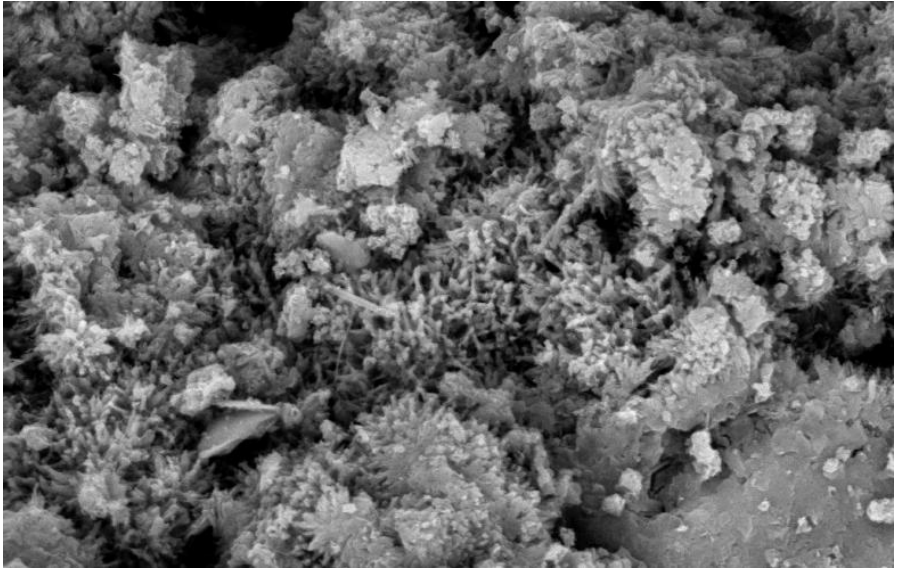

M1

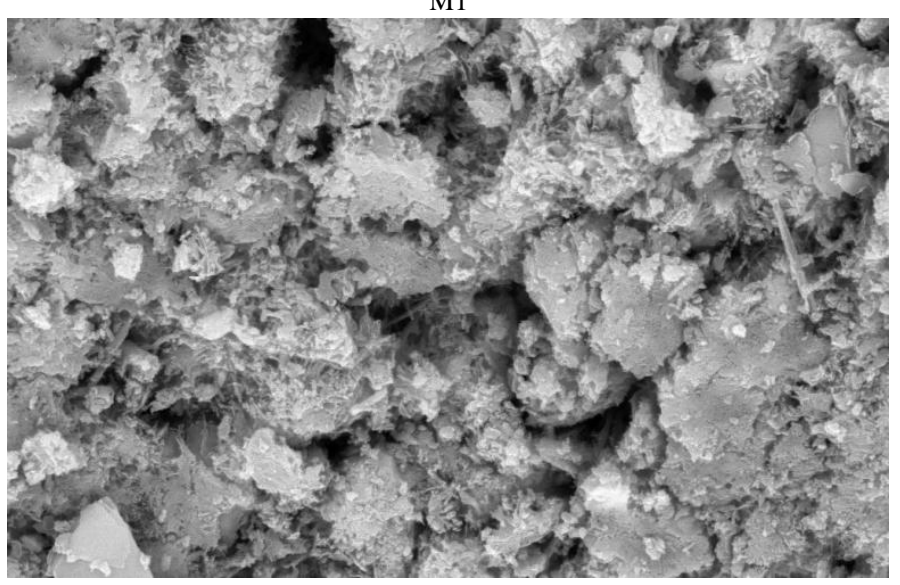

M3

Fig. 11: SEM Images of Blank PC (M0) and pastes premixed with Terpolymers.

\section{Conclusion}

In this study, a series of concrete admixtures, terpolymers [(MMA) n- (2-EHA) m- (MAA)L] was synthesized in various compositions of MMA and 2-EHA. The structure was confirmed by FTIR and ${ }^{1} \mathrm{H}$ NMR. Mixing the cement pastes with the terpolymers enhances most of the specific characteristics of the cement pastes. The obtained results confirmed the important role of W/C-ratio on the effectiveness of the added polymer so that their optimum values at $\mathrm{W} / \mathrm{C}=0.23$ shows that increasing the combined water content. However the setting times (initial and final) were extended. There is evidently an improvement in the compressive strength of premixed cement pastes with polymer for all experimentally polymer ratios at all curing ages of hydration compared with those of the pure cement pastes and good workability was achieved by mixing cement pastes with M2 \& M3 ratios. The absorption of water was reduced especially in presence of $62 \%$ ratio of MMA due to the lower the permeable pore volume of formed hydrates. The SEM micrographs illustrated that mixing the cement pastes with terpolymers do not affect the chemical composition of the PC hydration products, but also affects the physical properties such as, shape or morphology and the degree of crystallinity of the formed hydrates that converged from long and thin to short and compact needles. As remarked conclusion the properties of cement pastes are enhanced as the ratio of MMA in the prepared terpolymers increases. 


\section{Acknowledgements}

The authors gratefully acknowledge the funding provided by the European Union under the Marie Curie Actioninternational incoming fellowships (FP7-PEOPLE-2011-IIF), grant agreement PIIF-GA-2011 (Project No 300427) ProSeC for research on the production of sustainable self-compacting concrete.

\section{References}

[1] John Wiley \& Sons, Concrete Manual ( $8^{\text {th }}$ edition), New York, London, A Wiley-Inter-science Publication, (1981).

[2] Kung-Chung. H.; Sheng-Da. C.; Nan. S., Journal of Applied Polymer Science, 76, (2000), 1762.

[3] Ahmad, R., Iranian Polymer Journal, 10, (2001), 157.

[4] El-Sayed, Negim; Latipa, Kozhamzharova; Yeligbayeva, Gulzhakhan; Jamal, Khatib; Lyazzat, Bekbayeva; Craig, Williams, The Scientific Word Journal, 2014, (2014), 11. http://dx.doi.org/10.1155/2014/297431.

[5] El-Sayed, Negim; Latipa, Kozhamzharova; Jamal, Khatib; Lyazzat, Bekbayeva; Craig, Williams, the Scientific Word Journal, 2014, (2014), 10. http://dx.doi.org/10.1155/2014/297431.

[6] El-Sayed, Negim; Khatib, J.M.; Sakhy, M.; Shilibekov, S.; Shanshabayev, N.; Jakiyayev, B., World Applied Sciences Journal, 29, 6, (2014), 796-804.

[7] Ayoub, M.M.H; El-Awady, M.M.; Nasr, H.E.; Negim, S.M., J. Polymer-Plastics Technology and Engineering, 42, 5, (2003), 863-881.

[8] Ayoub, M.M.H; Nasr, H.E.; Darweesh, M.H.H.; Negim, S.M., J. Polymer-Plastics Technology and Engineering, 44, 2 , (2005), 305-319.

[9] Negim, S.M.; Ayoub, M.M.H.; Enany, G.M.; Mun, G.A., Eurasian ChemTech Journal, 8, 3, (2006), $243-250$.

[10] Ayoub, MMH; Darweesh, HHM; Negim, S.M., Cemento Hormigon, 919, (2007), 4-15.

[11] El-Sayed. Negim; Mahyuddin, Ramli; Saber, Mansour; Bahruddin, Saad; Muhammad, Saleh, Middle-East Journal of Scientific Research, 6, 2, (2010), 99-107.

[12] El-Sayed, Negim; Mahyuddin, Ramli; Saber, Mansour; Bahruddin, Saad; Muhammad, Idiris. J. World Applied Science, 10, 4, (2010), 443450 .

[13] El-Sayed, Negim; Jamal, Khatib; Mahyuddin, Ramli; Bahruddin, Saad; Muhammad, Saleh, J. World Applied Sciences, 10,6 , (2010), 685-694.

[14] El-Sayed, Negim; Mahyuddin, Ramli; Bahruddin, Saad; Lyazzat, Bekbayeva; Muhammad, Saleh. J. Polymer-Plastics Technology and Engineering, 50, (2011), 941 - 946. http://dx.doi.org/10.1080/03602559.2011.553861.

[15] El-Sayed, Negim; Mahyuddin, Ramli; Jamal, Khatib; Lyazzat, Bekbayeva; Muhammad, Saleh. Middle-East Journal of Scientific Research, 9, $1,(2011), 08-16$.

[16] Khatib, J.M.; Negim, S.M.; Tarek, Uddin, the Masterbuilder-Construction Chemicals, 14, 1, (2012), 142 - 149.

[17] El-Sayed, Negim; Jamal, Khatib; Khalid, Mutairi; Rakhmetullayeva, Raikhan; Mun, A. Grigoriy, Middle- East Journal of Scientific Research, $11,8,(2012), 1131-1139$.

[18] El-Sayed, Negim; Jamal, Khatib; Mohammed, Muhanna; Syrmanova, Kulash, World Applied Sciences Journal, 19,6 , (2012), 832-837.

[19] Negim, E.S.M.; Khatib, J.M.; Yeligbayeva, G.Zh.; Rakhmetullayeva, R.; Urkimbaeva, P.I.; Sakhy, M.; Shilibekov, S.; Mun, G.A., World Applied Sciences Journal, 25, 7, (2013), 1044-1052.

[20] El-Sayed, Negim; Jamal, Khatib; Nurlan, Inkarbekov, World Applied Sciences Journal, 23, 4, (2013), 549-553.

[21] ASTM C204-82, Standards Test Method, (1993).

[22] ASTM-Standards, Standard test method for normal consistency of hydraulic cement, C187-86, (1993), 148-150.

[23] ASTM-Standards, Standard test method for setting time of hydraulic cement by Vicat apparatus, C191-92, (1993), 866-868.

[24] ASTM-Standards, Standard test method for compressive strength of dimentional strones, C170-90, (1993), 828-830.

[25] El-Didamony, H.; Haggag, M.Y.; Abo-El-Enein, S.A., Cem. Concr. Res., 8, (1978), 351-358. http://dx.doi.org/10.1016/0008-8846 (78)90105$\underline{9}$.

[26] Satarin, V.I.; Syrkin, Y.M., Determination of Chemically-Bound Water in Rapid Hardening Slag Portland cement. Proc. $5^{\text {th }}$. Int. Symp. Chem. Tokyo, Japan, (1968), 215-227.

[27] ASTM C127 - 12. Standard Test Method for Density, Relative Density (Specific Gravity), and Absorption of Coarse Aggregate, DOI: 10.1520/C0127-12. http://dx.doi.org/10.1520/C0127-12.

[28] Amal, A.I.; Ahmed, A.; Mohamed, S.S.; Magdy M.H.A., Open Journal of Organic Polymer Materials, 2 , (2012), 23. http://dx.doi.org/10.4236/ojopm.2012.22004.

[29] Allahverdi, A.; Kianpur, K.; Moghbeli, M.R., Iranian Journal of Materials Science \& Engineerin. (2010), 7.

[30] Frank, W.; Stefan, B.; Joachim, P.; Thomas, G., Cement \& Concrete Composites, 29, (2007), 251. http://dx.doi.org/10.1016/j.cemconcomp.2006.12.006.

[31] Meishan, P.; Wanki, K.; Wongil, H.; Aaron, J. A.; Yangseob. S., Cement and Concrete Research, $32,(2002), 837$.

[32] Mohamed, H.; Mohamed, S.M.; Ismail. A., Ceramics - Silikáty, 50, (2006), 5.

[33] El-Sayed, M.N.; Mahyuddin, R.; Bahruddin, S.; Jamal, K.; Lyazzat, B.; Marwan, S.; Muhammad, I. S., Middle-East Journal of Scientific Research, 9, (2011), 08.

[34] Ayoub, M.M.H.; Nasr. H. E. Polymer - Plastics Technology and Engineering, 45, (2006), 1307. http://dx.doi.org/10.1080/03602550600950380.

[35] Joachim, S., Cement and Concrete Research, 29, (1999), 909. http://dx.doi.org/10.1016/S0008-8846 (99)00060-5.

[36] Chandra, S.; Flodin. P., Cement and Concrete Research, 17, (1987), 875. http://dx.doi.org/10.1016/0008-8846 (87)90076-7.

[37] Johann, P.; Christian. H., Cement and Concrete Research, 37, (2007), 537. 